\title{
Therapeutic effects of $\gamma$-irradiation in a primary effusion lymphoma mouse model
}

\author{
YOSHIOKI SHIRAISHI ${ }^{1,2}$, KUMIKO GOTOH ${ }^{1,2}$, TOMOMI TOWATA ${ }^{1}$, TATSUYA SHIMASAKI ${ }^{2}$, \\ SHINYA SUZU ${ }^{1}$, AKIHIRO KOJIMA ${ }^{2}$ and SEIJI OKADA ${ }^{1,2^{*}}$ \\ ${ }^{1}$ Division of Hematopoiesis, Center for AIDS Research; ${ }^{2}$ Radioisotope Center, \\ Institute of Resource Development and Analysis, Kumamoto University, Kumamoto 860-0811, Japan
}

Received August 27, 2009; Accepted October 27, 2009

DOI: 10.3892/etm_00000014

\begin{abstract}
Primary effusion lymphoma (PEL) is a unique and recently identified non-Hodgkin's lymphoma in immunocompromised individuals. PEL is caused by the Kaposi sarcoma-associated herpes virus/human herpes virus 8 (KSHV/ $\mathrm{HHV}-8$ ) and has a peculiar presentation involving liquid growth in the serous body cavity, chemotherapy resistance and poor prognosis. In search of a new therapeutic modality for PEL, we examined the effect of $\gamma$-irradiation on PEL-derived cell lines (BCBL-1, BC-1, and BC-3) in vitro and in vivo. An MTT assay and trypan blue exclusion assay revealed that irradiation significantly suppressed cell proliferation in the PEL cell lines in a dose-dependent manner, and induced apoptosis. The PEL cell lines were relatively radiosensitive compared with other hematological tumor cell lines (Raji, Jurkat, and K562 cells). Inoculation of the $\mathrm{BC}-3$ cell line into the peritoneal cavity of Rag2/Jak3 double-deficient mice led to massive ascites formation, and subcutaneous injection of BCBL-1 led to solid lymphoma formation. Total body irradiation (4 Gy x 2) with bone marrow transplantation resulted in the complete recovery of both types of PEL-inoculated mice. These results suggest that total body irradiation with bone marrow transplantation can be successfully applied for the treatment of chemotherapyresistant PEL.
\end{abstract}

\section{Introduction}

Primary effusion lymphoma (PEL) is a unique form of non-Hodgkin's lymphoma that mainly occurs in severely immunocompromised HIV-positive patients $(1,2)$. PEL is etiologically related to human herpes virus-8 (HHV-8) and usually presents as lymphomatous body cavity effusion (pleural, pericardial and peritoneal) in the absence of a solid

Correspondence to: Dr Seiji Okada, Division of Hematopoiesis, Center for AIDS Research, Kumamoto University, 2-2-1 Honjo, Kumamoto 860-0811, Japan

E-mail: okadas@kumamoto-u.ac.jp

Key words: primary effussion lymphoma, radiosensitivity, animal model tumor mass. Among AIDS-related lymphomas, PEL generally has an extremely aggressive clinical course with a median survival ranging from 2 to 6 months (3). Its prognosis remains poor even after the advent of highly active anti retroviral treatment (HAART) (2). PEL is well known to have strong chemotherapy resistance, and most PEL patients do not respond to combination chemotherapy, such as CHOP. Thus, the optimal treatment for PEL has not yet been defined, and novel effective agents are expected.

Radiotherapy, including total body irradiation, is a crucial treatment option for hematological malignancies, in particular malignant lymphoma $(4,5)$. The treatment of lymphoma depends on numerous factors, including stage, grade, age, and performance status. Since the total irradiation dose for patients is limited, radiotherapy has been used to treat bulky masses, extranodal sites and low-grade stage IA patients.

Here, we examined the radiation sensitivity of PEL cell lines. PEL cells were sensitive to $\gamma$-irradiation as compared with other hematological malignant cells. Using an in vivo immunodeficient mice model bearing the PEL cell line, we also demonstrated the inhibition of tumor cell growth by total body irradiation. Our findings suggest that radiotherapy can be successfully applied for the treatment of this chemotherapyresistant malignant lymphoma.

\section{Materials and methods}

Cell lines and radiation exposure device. The human PEL cell lines BCBL-1 (obtained through the AIDS Research and Reference Reagent Program, Division of AIDS, NIAID, NIH) (6), BC-1 (7) and BC-3 (8) (purchased from the American Type Culture Collection, Manassas, VA), and the non-PEL human leukemic cell lines Raji, Jurkat and K562 (obtained from RIKEN Cell Bank, Tsukuba, Japan) were maintained in RPMI1640 supplemented with $10 \%$ heat-inactivated fetal calf serum, penicillin $(100 \mathrm{U} / \mathrm{ml})$ and streptomycin $(100 \mu \mathrm{g} / \mathrm{ml})$ in a humidified incubator at $37^{\circ} \mathrm{C}$ and $5 \% \mathrm{CO}_{2}$. The cells and mice were irradiated at a dose rate of $0.9 \mathrm{~Gy} / \mathrm{min}$ to a total dose of 1-10 Gy using a ${ }^{137} \mathrm{Cs}$ source (Gammacell 40 Exactor; MDS Nordion Inc., Ottawa, Canada).

MTT assay. The antiproliferative effects of $\gamma$-irradiation on PEL and non-PEL leukemic cell lines were measured by the 
tetrazolium dye methylthiotetrazole (MTT) method (Sigma, St. Louis, MO). Briefly, $2 \times 10^{4}$ cells were incubated in triplicate in a 96-well microculture plate in the presence of various doses of ionized irradiation in a final volume of $0.1 \mathrm{ml}$ for $48 \mathrm{~h}$ at $37^{\circ} \mathrm{C}$. Subsequently, MTT $(0.5 \mathrm{mg} / \mathrm{ml}$ final concentration $)$ was added to each well. After $4 \mathrm{~h}$ of additional incubation, $100 \mu \mathrm{l}$ of a solution containing 10\% SDS plus $0.01 \mathrm{~N} \mathrm{HCl}$ was added to dissolve the crystal. Absorption values at $595 \mathrm{~nm}$ were determined with an automatic ELISA plate reader (Multiskan; Thermo Electron Vantaa, Finland). Values were normalized to untreated (control) samples.

DNA fragmentation assay. To characterize the cell death pattern, DNA ladder assays were performed as previously described (9). Briefly, $1 \times 10^{6}$ cells were lysed in $100 \mu \mathrm{l}$ of $10 \mathrm{mM}$ Tris-HCl buffer (pH 7.4) containing $10 \mathrm{mM}$ EDTA and $0.5 \%$ Triton X. After centrifugation for $5 \mathrm{~min}$ at 15,000 rpm, supernatant samples were treated with RNase A (Sigma) and Proteinase K (Wako Pure Chemical, Osaka, Japan). Subsequently, $20 \mu \mathrm{l}$ of $5 \mathrm{M} \mathrm{NaCl}$ and $120 \mu \mathrm{l}$ isopropanol were added, and the sample was maintained at $-20^{\circ} \mathrm{C}$ for $6 \mathrm{~h}$. Following centrifugation for $15 \mathrm{~min}$ at $15,000 \mathrm{rpm}$, the pellets were dissolved in $20 \mu \mathrm{l}$ of TE buffer $(10 \mathrm{mM}$ Tris- $\mathrm{HCl}$ and $1 \mathrm{mM}$ EDTA) as loading samples. To assess the DNA fragmentation pattern, samples were loaded onto $1.5 \%$ agarose gel and electrophoresis was performed.

Flow cytometric analysis of DNA fragmentation. PEL cells were incubated in hypotonic lysing buffer $(0.1 \%$ sodium citrate, $0.1 \%$ Triton $\mathrm{X}, 0.1 \%$ RNase A and $50 \mu \mathrm{g} / \mathrm{ml}$ propidium iodide (PI) at $4^{\circ} \mathrm{C}$ for $4 \mathrm{~h}(10)$. DNA content in each cell was analyzed on an LSR II flow cytometer (BD Biosciences, San Jose, CA). Data were analyzed using FlowJo software (Tree Star, San Carlos, CA).

Annexin $V$ assay. Apoptosis was quantified using the Annexin V-PE Apoptosis Detection kit I (BD Biosciences). Briefly, after $\gamma$-irradiation, cells were harvested, washed, and then incubated with Annexin V-PE and 7-AAD for $15 \mathrm{~min}$ in the dark, before being analyzed on an LSR II cytometer.

Xenograft and radiotherapy mouse model. Balb/c Rag-2 deficient (Rag-2-/) mice and Balb/c Jak3-deficient (Jak3 $3^{-/}$) mice were established by crossing Rag- $2^{-/-}$mice (11) or Jak $3^{-/-}$mice (12) with the Balb/c strain for 10 generations, respectively. Balb/c Rag-2/Jak3 double deficient (Rag-2-/Jak3 ${ }^{-/-}$) mice were established by crossing Balb/c Rag- $2^{-/-}$mice and Balb/c Jak3 $3^{-/-}$ mice, and were housed and monitored in our animal research facility according to institutional guidelines. Experimental procedures and protocols were approved by the Institutional Animal Care and Use Committee of Kumamoto University. In a subcutaneous xenograft mouse model, 8- to 10-week-old Rag- $2^{-/-J a k} 3^{-/-}$mice were subcutaneously inoculated with $5 \times 10^{6}$ BCBL-1 cells suspended in $200 \mu \mathrm{l}$ PBS. In an intraperitoneal xenograft mouse model, Rag- $2^{--} \mathrm{Jak}^{-/-}$mice were intraperitoneally inoculated with $5 \times 10^{6} \mathrm{BC}-3$ cells suspended in $200 \mu \mathrm{l}$ PBS. Seven days after the xenotransplantation of PEL cells, the recipient mice were irradiated (4 Gy x 2), and the bone marrow cells from Rag- $2^{-/-J a k} 3^{-/}$mice were transplanted into irradiated mice. Tumor burden was evaluated by measuring
A

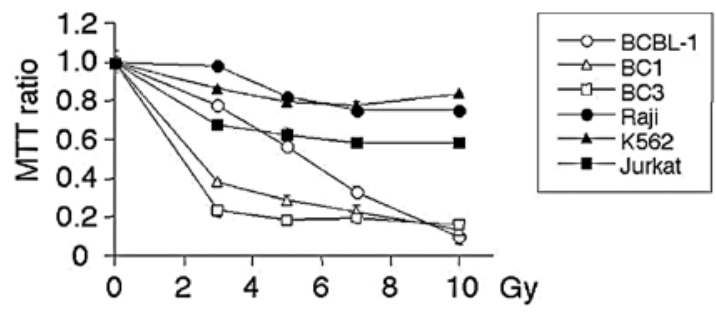

B
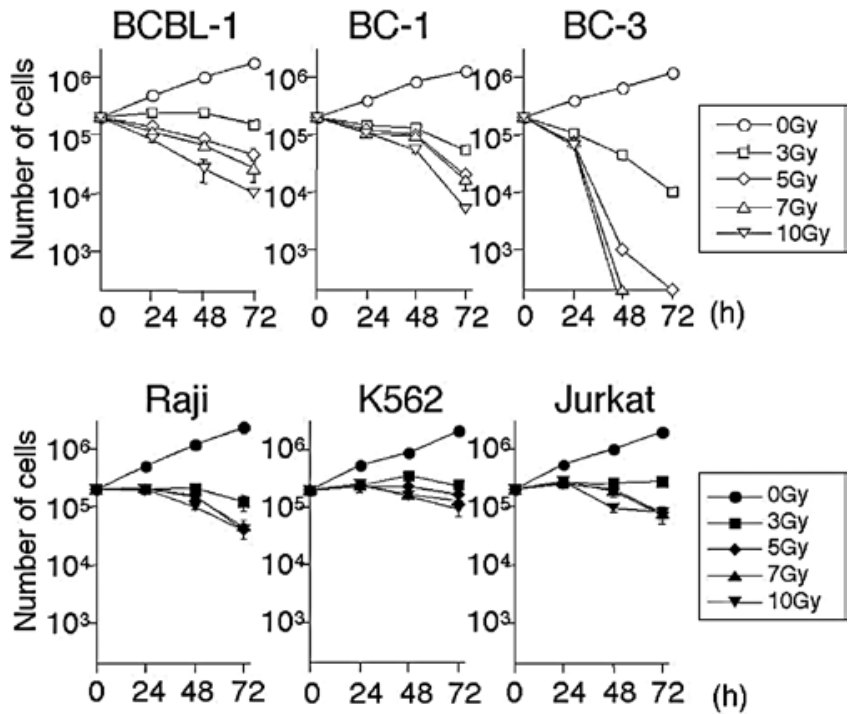

Figure 1. Radiation inhibits the proliferation of PEL cells. (A) PEL cell lines (BCBL-1, BC-1 and BC-3) and non-PEL cell lines (Raji, Jurkat and K562) were irradiated with 3, 5, 7 and 10 Gy and cultured for 3 days. A cell proliferation assay was carried out using the MTT assay (see Materials and methods). One representative result from 3 independent experiments is shown. (B) PEL cell lines (BCBL-1, BC-1 and BC-3) and non-PEL cell lines (Raji, Jurkat and K562) were irradiated with 3, 5, 7 and 10 Gy and cultured for 3 days. Cell counting was carried out every $24 \mathrm{~h}$ using a hematimeter. A representative result of 3 independent experiments is shown.

the tumor mass body weight, or ascites. Tumor growth was monitored by measuring maximal and minimal diameters with calipers every week, and tumor size was estimated with the formula: tumor size $\left(\mathrm{mm}^{3}\right)=$ length $(\mathrm{mm}) \mathrm{x}$ width $^{2}(\mathrm{~mm})$ $\mathrm{x} 0.4$, as described previously $(13,14)$. For assessment of disease-free survival, Kaplan-Meier analysis was performed and $\mathrm{P}$-values were determined by 2 -tailed analysis with logrank tests.

Statistical analysis. Assays were performed in triplicate and expressed as the mean \pm SD. The statistical significance of differences observed between experimental groups was determined using the Student's t-test. P-values $<0.05$ were considered significant.

\section{Results}

Inhibitory effect of ionized irradiation on the proliferation of PEL cell lines. Initially, the radiosensitivity of PEL cells was examined. Three PEL cell lines (BCBL-1, BC-1 and BC-3) and three non-PEL cell lines (Raji, B lymphoid; Jurkat, 
A

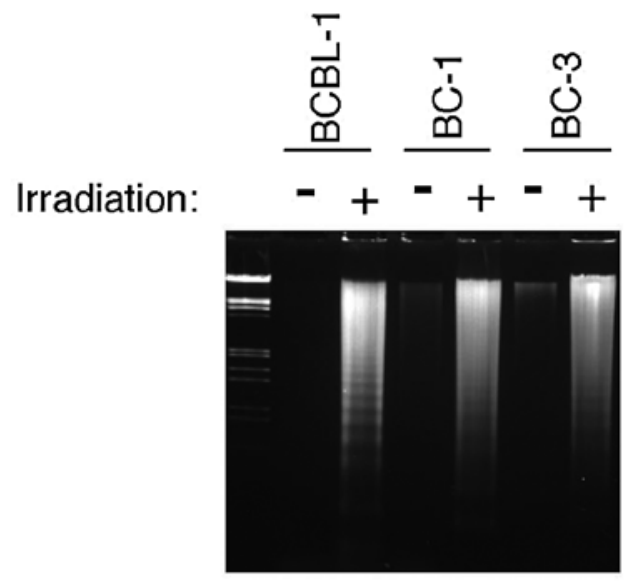

B

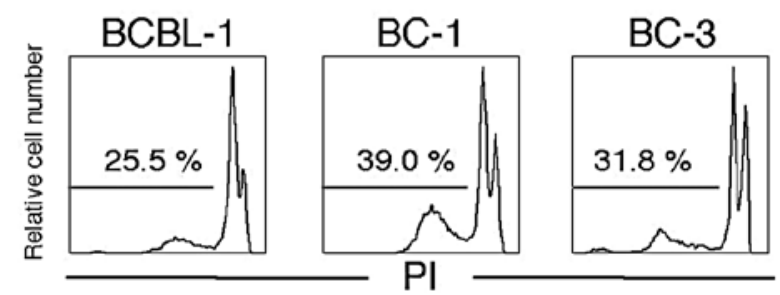

C

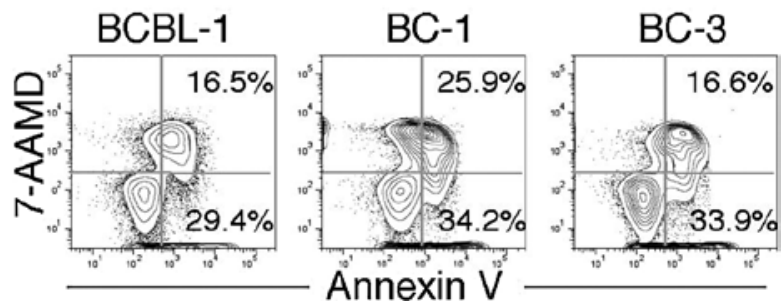

Figure 2. Irradiation induces the apoptosis of PEL cells. (A) Induction of apoptosis in PEL cells by ionized irradiation (ladder formation). Irradiated (5 Gy) or non-irradiated PEL cells were cultured for $48 \mathrm{~h}$. DNA was extracted and separated by electrophoresis on 1.5\% agarose gel. (B) Apoptosis was determined by flow cytometric analysis of DNA fragmentation using PI staining. (C) Radiation-induced apoptosis as detected by Annexin V and 7-AAD dual staining. The PEL cell lines BCBL-1, BC-1 and BC-3 were irradiated (5 Gy), cultured for $72 \mathrm{~h}$, and subsequently stained with Annexin-PE and 7-AAD before being analyzed by flow cytometry. A representative result of 3 independent experiments is shown.

T lymphoid; and K562, erythroleukemia) were cultured after irradiation $(0,3,5,7$ and $10 \mathrm{~Gy})$ for 3 days, and proliferation was analyzed by the MTT assays. As shown in Fig. 1, irradiation inhibited cell growth in a dose-dependent manner in all PEL and non-PEL cell lines. PEL cell lines were more sensitive than non-PEL cell lines to radiotherapy. The effects of irradiation were then confirmed by traditional cell count. PEL and non-PEL cell lines were cultured after irradiation ( 0 , 3, 5, 7 and $10 \mathrm{~Gy}$ ) for 3 days, and cell numbers were counted by trypan blue staining. As shown in Fig. 1B, the number of PEL cells decreased in a dose- and time-dependent manner. In contrast, non-PEL cells survived, indicating that PEL cells are more sensitive to irradiation.

Induction of apoptosis in PEL cells by $\gamma$-irradiation. To determine whether growth inhibition by ionized irradiation
A Non-irradiated

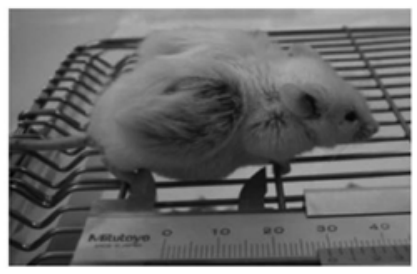

Irradiated

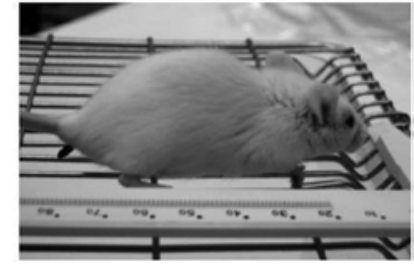

B

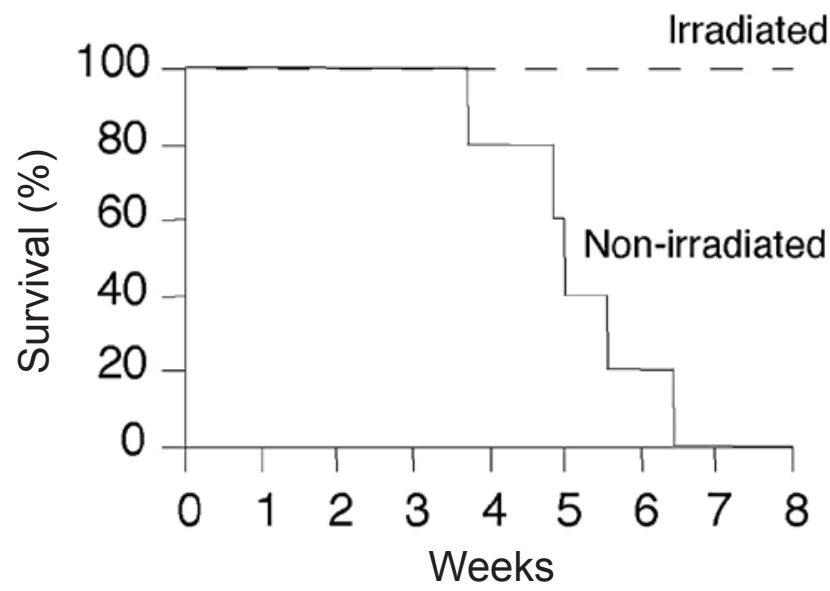

C

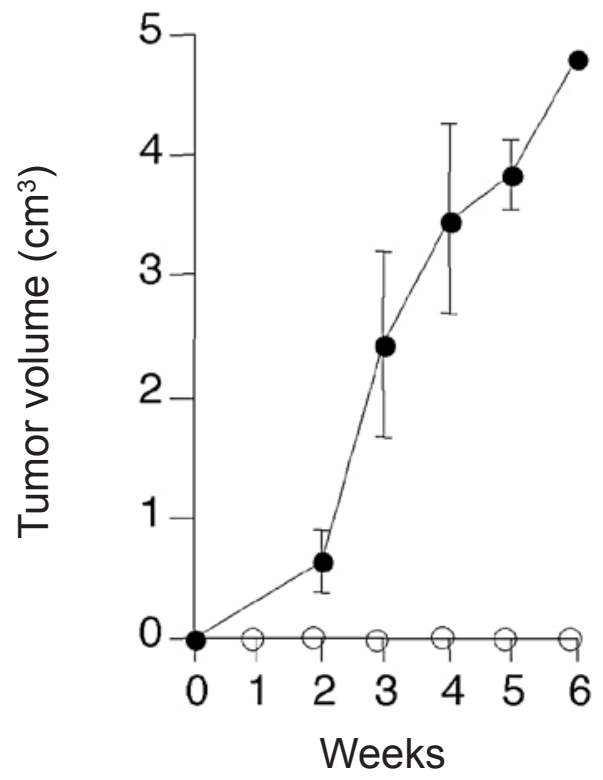

Figure 3. Inhibition of subcutaneously inoculated PEL cell growth by irradiation in vivo. (A) Irradiated and non-irradiated mice 4 weeks after subcutaneous inoculation with BCBL-1. (B) Anti-tumor effect of ionized irradiation (survival). All non-irradiated PEL mice died within $\sim 6$ weeks, while the irradiated mice survived. (C) Tumor volume of mice inoculated with BCBL-1 cells and irradiated or non-irradiated, expressed as the mean \pm SD from 5 mice and the tumor volume of each mouse $(\mathrm{P}<0.05)$.

was attributable to apoptosis in PEL cells, DNA fragmentation analysis (ladder formation and detection of the sub-G1 fraction by flow cytometry) was performed $48 \mathrm{~h}$ after ionized irradiation. As shown in Fig. 2A, irradiation caused DNA 


\section{Non-irradiated Irradiated}
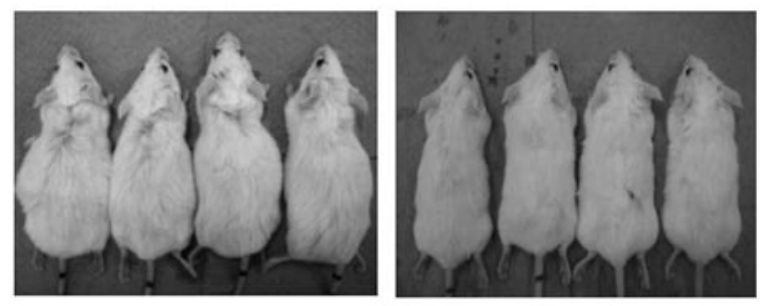

B

C

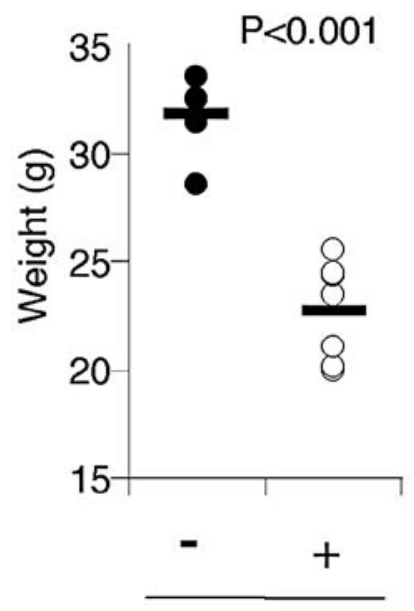

Irradiation

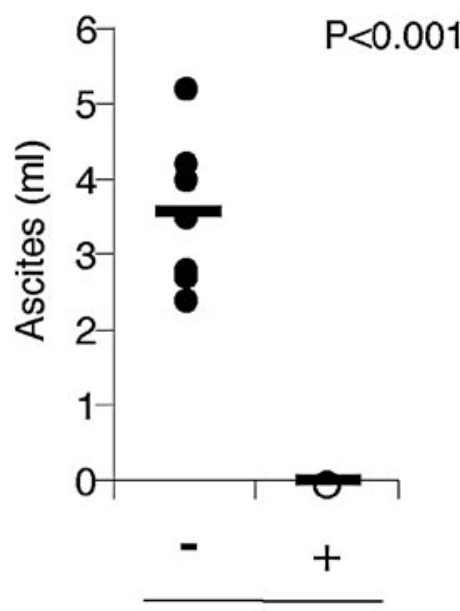

Irradiation

Figure 4. Inhibition of ascites formation in mice inoculated with PEL cells that underwent total body irradiation. (A) Ascites-bearing non-irradiated PEL mice and irradiated PEL mice (6 weeks after inoculation). (B) Body weight of mice inoculated with $\mathrm{BC} 3$ cells and irradiated or non-irradiated mice. (C) Volume of ascites inoculated with BC3 cells and irradiated or non-irradiated mice.

fragmentation, which is a characteristic of apoptotic cell death (9). In addition, sub-G1 populations (the apoptotic fraction) were detected in all three PEL cell lines (Fig. 2B).

An Annexin $\mathrm{V}$ binding assay was also performed for further confirmation of irradiation-induced apoptosis in PEL cells. The annexin positive 7-AAD negative fraction represents the early phase of apoptosis, whereas the Annexin positive 7-AAD positive fraction represents the late phase of apoptosis and necrosis. (15). As shown in Fig. 2C, irradiation induced apoptosis in PEL cell lines. These results suggest that growth inhibition by irradiation occurs via the induction of apoptosis.

In vivo effects of irradiation on severe immunodeficient mice inoculated with a PEL cell line. Since the above results suggested the efficacy of radiotherapy for the treatment of PEL patients, we next examined the in vivo effects of irradiation in an immunodeficient mice model. Severe immunodeficient Rag-2/-Jak3 ${ }^{-/}$mice were inoculated subcutaneously with $5 \times 10^{6}$ BCBL-1 cells. Seven days after the xenotransplantation of the BCBL-1 cells, the recipient mice were irradiated (4 Gy x 2). Total bone marrow cells from Rag-2 $2^{--} \mathrm{Jak}^{-/-}$mice $\left(1 \times 10^{7} /\right.$ mouse) were transplanted into the irradiated mice. Non-irradiated mice efficiently developed large subcutaneous

tumors (Fig. 3A), exhibited clinical signs of near-death, such as piloerection, weight loss and cachexia, and succumbed within 3-6 weeks of transplantation (Fig. 3B and C). On the other hand, irradiated mice did not develop tumors and survived for more than 3 months after transplantation without developing tumors.

Since the formation of massive effusion is the nature of PEL, Rag-2/Jak3 double-deficient mice were inoculated intraperitoneally with $5 \times 10^{6}$ BC-3 cells. BC-3 produced massive ascites within 6 weeks of inoculation $(3.5 \pm 1.0 \mathrm{ml}, \mathrm{n}=7)$ (Fig. 4A) and body weight was significantly increased in mice (Fig. 4B), indicating that this was a clinically relevant PEL model.

The irradiated mice appeared to be healthy, with the same body weight as non-tumor inoculated mice, and did not have ascites (Fig. 4B). The body weight of non-irradiated mice was significantly increased by massive ascites compared with that of irradiated mice $(31.7 \pm 1.6 \mathrm{~g}$ vs. $22.8 \pm 2.3 \mathrm{~g}, \mathrm{n}=7, \mathrm{P}<0.001)$.

These data indicate that $\gamma$-irradiation significantly inhibits the growth and infiltration of PEL cells in vivo.

\section{Discussion}

In the present study, we investigated the direct effects of $\gamma$-irradiation on PEL cells in vitro and in vivo. PEL cells were relatively radiosensitive compared with other hematological malignant cells in vitro, and total body irradiation with bone marrow transplantation rescued PEL-inoculated Rag-2/Jak3 double-deficient mice, preventing the formation of tumors and effusions. Thus, we suggest that $\gamma$-irradiation is a promising candidate for chemotherapy-resistant PEL.

PEL is a rare high-grade B-cell malignancy associated with herpes virus HHV-8 infection, and is mainly observed during the course of HIV infection. The outcome of PEL after polychemotherapy, such as CHOP, has generally been poor, even since the advent of HAART. The potential for methotrexate to diffuse in serous cavities suggests the use of high-dose methotrexate in association with a CHOP-derived regimen (16); however, it has been reported that patients with serous effusion might be at increased risk of toxicity following high-dose methotrexate chemotherapy (17). In addition, there are reports in which even intensive treatment regimens were unsuccessful (18). Thus, the optimal treatment for PEL has not yet been defined. HHV-8 contains a homologue of cellular FLIP protein called vFLIP that has the ability to activate the NF- $\kappa \mathrm{B}$ pathway (19), which is known to protect against apoptosis induced by diverse stimuli (19-21). The NF- $\kappa \mathrm{B}$ pathway is known to induce the expression of a number of anti-apoptotic genes, such as Bcl-xL, A1, cIAP1, cIAP2, XIAP and IEX-1 (22). In addition, it has been demonstrated that the inhibition of NF- $\mathrm{KB}$ induces the apoptosis of PEL cells $(23,24)$. vFLIPmediated NF- $\kappa \mathrm{B}$ activation is necessary for the survival of PEL cells, and may cause them to become chemoresistant. Thus, the NF- $\kappa \mathrm{B}$ pathway represents an appropriate target for the molecular therapy of PEL, and several NF- $\kappa B$ inhibitors are already potential candidates (24-26). One of these candidates, the proteasome inhibitor bortezomib, has been shown to inhibit NF- $\kappa \mathrm{B}$ activity and induce the apoptosis of PEL cell lines in vitro $(27,28)$; however, bortezomib failed to control the progression of PEL in a clinical trial (29), indicating that 
preclinical anti-tumor activity does not necessarily translate directly into activity in patients, and that preclinical studies using animal models are required to determine the actual advantage of NF- $\kappa B$ inhibitors in PEL (29).

Malignant lymphomas are characterized by a high degree of radioresponsiveness. Consequently, radiotherapy is an important modality in controlling these malignancies (30). However, as most lymphomas are systemic diseases that are chemotherapy sensitive, use of radiotherapy has been limited to localized lymphomas. Recently, it was reported that chemotherapy-refractory HIV-associated PEL patients achieved remission and survived for more than 12 months (31). Our findings also suggest that PEL is sensitive to radiation treatment (Fig. 1). In addition, it has been shown that the in vitro radiosensitivity of tumor cells correlates with the response to therapeutic irradiation (32). Thus, radiotherapy should be considered as part of the treatment recommendation for patients with chemotherapy-refractory PEL.

In vivo experiments showed that non-treated mice subcutaneously xenografted with PEL developed large tumors, while peritoneally xenografted mice gained body weight and effusion in the peritoneal cavity (Figs. 3 and 4). On the other hand, the irradiated groups did not have either effusions or tumors for 12 weeks, indicating that irradiation is capable of rescuing PEL-xenografted mice. Animal models of human malignancies have been applied to study the nature of cancer stem cells and to assess the therapeutic effects of novel therapeutic strategies against malignant neoplasms $(33,34)$. In particular, the recent introduction of severe immunodeficient mice has enabled us to develop mice mimicking hematologic malignancies $(26,35)$. In this study, we used PEL-xenografted Rag2/ Jak3 double-deficient mice resembling the diffuse nature of human PEL, which is quite useful to assess the therapeutic efficacy of $\gamma$-irradiation in mice in a hematological malignancy model.

In summary, the present study demonstrated that $\gamma$-irradiation is quite effective for the treatment of PEL both in vitro and in vivo. Our study shows the usefulness of radiotherapy for the treatment of chemotherapy-resistant PEL patients. Radiotherapy should therefore be considered for the treatment of chemotherapy-resistant PEL patients.

\section{Acknowledgments}

We thank Ms. I. Suzu for technical assistance and Ms. Y. Endo and Ms. K. Tokunaga for secretarial assistance. This work was supported in part by a Health and Labour Sciences Research Grants from the Ministry of Health, Labour and Welfare of Japan (H19-AIDS-003), by a Grant-in-Aid for Scientific Research (C) from the Japan Society for the Promotion of Science (JSPS) and by the Global COE Program 'Global Education and Research Center Aiming at the Control of AIDS' from the Ministry of Education, Culture, Sports, Science and Technology (MEXT) of Japan.

\section{References}

1. Nador RG, Cesarman E, Chadburn A, et al: Primary effusion lymphoma: a distinct clinicopathologic entity associated with the Kaposi's sarcoma-associated herpes virus. Blood 88: 645-656, 1996.
2. Chen YB, Rahemtullah A and Hochberg E: Primary effusion lymphoma. Oncologist 12: 569-576, 2007.

3. Cesarman E, Chang Y, Moore PS, et al: Kaposi's sarcomaassociated herpesvirus-like DNA sequences in AIDS-related body-cavity-based lymphomas. N Engl J Med 332: 1186-1191, 1995.

4. Lee CK: Evolving role of radiation therapy for hematologic malignancies. Hematol Oncol Clin North Am 20: 471-503, 2006.

5. Gustavsson A, Osterman B and Cavallin-Stahl E: A systematic overview of radiation therapy effects in non-Hodgkin's lymphoma. Acta Oncol 42: 605-619, 2003.

6. Renne R, Zhong W, Herndier B, et al: Lytic growth of Kaposi's sarcoma-associated herpesvirus (human herpesvirus 8 ) in culture. Nat Med 2: 342-346, 1996.

7. Cesarman E, Moore PS, Rao PH, et al: In vitro establishment and characterization of two acquired immunodeficiency syndromerelated lymphoma cell lines (BC-1 and BC-2) containing Kaposi's sarcoma-associated herpesvirus-like (KSHV) DNA sequences. Blood 86: 2708-2714, 1995.

8. Arvanitakis L, Mesri EA, Nador RG, et al: Establishment and characterization of a primary effusion (body cavity-based) lymphoma cell line (BC-3) harboring kaposi's sarcoma-associated herpesvirus (KSHV/HHV-8) in the absence of Epstein-Barr virus. Blood 88: 2648-2654, 1996.

9. Sellins KS and Cohen JJ: Gene induction by gamma-irradiation leads to DNA fragmentation in lymphocytes. J Immunol 139: 3199-3206, 1987.

10. Nicoletti I, Migliorati G, Pagliacci MC, et al: A rapid and simple method for measuring thymocyte apoptosis by propidium iodide staining and flow cytometry. J Immunol Methods 139: 271-279, 1991.

11. Shinkai Y, Rathbun G, Lam KP, et al: RAG-2-deficient mice lack mature lymphocytes owing to inability to initiate $\mathrm{V}(\mathrm{D}) \mathrm{J}$ rearrangement. Cell 68: 855-867, 1992.

12. Park SY, Saijo K, Takahashi T, et al: Developmental defects of lymphoid cells in Jak3 kinase-deficient mice. Immunity 3: 771-782, 1995

13. Attia MA and Weiss DW: Immunology of spontaneous mammary carcinomas in mice. V. Acquired tumor resistance and enhancement in strain A mice infected with mammary tumor virus. Cancer Res 26: 1787-1800, 1966.

14. Harada H, Suzu S, Ito $\mathrm{T}$, et al: Selective expansion and engraftment of human CD16+ NK cells in NOD/SCID mice. Eur J Immunol 35: 3599-3609, 2005.

15. Vermes I, Haanen C, Steffens-Nakken H, et al: A novel assay for apoptosis. Flow cytometric detection of phosphatidylserine expression on early apoptotic cells using fluorescein labelled Annexin V. J Immunol Methods 184: 39-51, 1995.

16. Boulanger E, Daniel MT, Agbalika F, et al: Combined chemotherapy including high-dose methotrexate in KSHV/ HHV8-associated primary effusion lymphoma. Am J Hematol 73: 143-148, 2003.

17. Pauley JL, Panetta JC, Schmidt J, et al: Late-onset delayed excretion of methotrexate. Cancer Chemother Pharmacol 54: 146-152, 2004.

18. Waddington TW and Aboulafia DM: Failure to eradicate AIDS-associated primary effusion lymphoma with high-dose chemotherapy and autologous stem cell reinfusion: case report and literature review. AIDS Patient Care STDS 18: 67-73, 2004.

19. Liu L, Eby MT, Rathore N, et al: The human herpes virus 8-encoded viral FLICE inhibitory protein physically associates with and persistently activates the Ikappa B kinase complex. J Biol Chem 277: 13745-13751, 2002.

20. Chaudhary PM, Jasmin A, Eby MT, et al: Modulation of the NF-kappa B pathway by virally encoded death effector domainscontaining proteins. Oncogene 18: 5738-5746, 1999.

21. Sun Q, Matta H and Chaudhary PM: The human herpes virus 8 -encoded viral FLICE inhibitory protein protects against growth factor withdrawal-induced apoptosis via NF-kappa B activation. Blood 101: 1956-1961, 2003.

22. Mayo MW and Baldwin AS: The transcription factor NF-kappaB: control of oncogenesis and cancer therapy resistance. Biochim Biophys Acta 1470: M55-M62, 2000.

23. Keller SA, Schattner EJ and Cesarman E: Inhibition of NF-kappaB induces apoptosis of KSHV-infected primary effusion lymphoma cells. Blood 96: 2537-2542, 2000.

24. Dabaghmanesh N, Matsubara A, Miyake A, et al: Transient inhibition of NF-kappaB by DHMEQ induces cell death of primary effusion lymphoma without HHV-8 reactivation. Cancer Sci 100: 737-746, 2009. 
25. Keller SA, Hernandez-Hopkins D, Vider J, et al: NF-kappaB is essential for the progression of KSHV- and EBV-infected lymphomas in vivo. Blood 107: 3295-3302, 2006.

26. Takahashi-Makise N, Suzu S, Hiyoshi M, et al: Biscoclaurine alkaloid cepharanthine inhibits the growth of primary effusion lymphoma in vitro and in vivo and induces apoptosis via suppression of the NF-kappaB pathway. Int J Cancer 125: 1464-1472, 2009.

27. McConkey D, Nawrocki ST and Andtbacka R: Velcade displays promising activity in primary effusion lymphoma cells. Cancer Biol Ther 4: 491-492, 2005.

28. An J, Sun Y, Fisher M, et al: Antitumor effects of bortezomib (PS-341) on primary effusion lymphomas. Leukemia 18: 1699-1704, 2004.

29. Boulanger E, Meignin V and Oksenhendler E: Bortezomib (PS-341) in patients with human herpesvirus 8-associated primary effusion lymphoma. Br J Haematol 141: 559-561, 2008.
30. Gospodarowicz M: Radiotherapy in non-Hodgkin lymphomas. Ann Oncol 19 (Suppl 4): iv47-iv50, 2008.

31. Cassoni A, Ali U, Cave J, et al: Remission after radiotherapy for a patient with chemotherapy-refractory HIV-associated primary effusion lymphoma. J Clin Oncol 26: 5297-5299, 2008.

32. Dubray B, Breton C, Delic J, et al: In vitro radiation-induced apoptosis and early response to low-dose radiotherapy in nonHodgkin's lymphomas. Radiother Oncol 46: 185-191, 1998.

33. Bankert RB, Hess SD and Egilmez NK: SCID mouse models to study human cancer pathogenesis and approaches to therapy: potential, limitations, and future directions. Front Biosci 7: c44-c62, 2002.

34. Bankert RB, Egilmez NK and Hess SD: Human-SCID mouse chimeric models for the evaluation of anti-cancer therapies. Trends Immunol 22: 386-393, 2001.

35. Shultz LD, Ishikawa F and Greiner DL: Humanized mice in translational biomedical research. Nat Rev Immunol 7: 118-130, 2007. 